\title{
Abdominal Skin Necrosis after Enoxaparin Treatment
}

\author{
Haddad Maruan, Nierenberg Gabriel, Falah Mazen, Rosenberg Nahum* \\ Orthopedic Surgery Department, Rambam-Health Care Campus, Haifa, Israel \\ Email: ${ }^{*}$ nahumrosenberg@hotmail.com
}

Received 21 January 2014; revised 21 February 2014; accepted 28 February 2014

Copyright (C) 2014 by authors and Scientific Research Publishing Inc.

This work is licensed under the Creative Commons Attribution International License (CC BY). http://creativecommons.org/licenses/by/4.0/

(c) (i) Open Access

\begin{abstract}
Subcutaneous low molecular weight heparin (LMWH) injection is a prophylactic treatment for deep vein thrombosis after surgery in lower limb before the patient is fully ambulated. This treatment is usually safe. One of the major and rare complications of the LMWH injection is thrombocytopenia, which is usually self-limiting. We present a rare case of patient with thrombocytopenia, induced by subcutaneous injection of LMWH (enoxaparin) that was complicated with a large hematoma at the injection site with subsequential skin necrosis, sepsis with fatal outcome. We would like to emphasize this rare complication of the common prophylactic treatment by LMWH in order to pursue this diagnosis when similar cutaneous manifestation might appear in patients who receive prophylactic treatment with LMWH.
\end{abstract}

\section{Keywords}

Heparin Induced Thrombocytopenia; Skin Necrosis; Heparin; Low Molecular Weight Heparin

\section{Introduction}

Prophylactic treatment of deep venous thrombosis (DVT) is necessary in certain clinical conditions, especially when prolonged bed rest is expected. Currently the low molecular weight heparin (LMWH) is considered as a gold standard prophylactic antithrombotic pharmacological agent for this purpose. Additionally other pharmacological means are available, e.g. high molecular weight heparin, warfarin, acetylsalicylic acid and the new generation of factor $\mathrm{X}$ inhibitors [1].

Enoxaparin (enoxaparin sodium), a low molecular weight heparin,is used to treat and prevent deep vein thrombosis. This antithrombotic agent acts on the coagulation factors Xa and IIa and prevents the conversion of prothrombin to thrombin and of thrombin to fibrin. This agent has been shown to be a very effective and highly

"Corresponding author. 
safe pharmacological anticoagulant in several clinical trials [1] [2]; therefore it is widely clinically used. Some rare, but important side effects following administration of LMWH, including skin reactions, have been noticed and studied previously [3] [4]. A complication of massive skin necrosis following subcutaneous enoxaparin administration is rare. This adverse effect of LMWH treatment should be diagnosed because of its potential fatality. We encountered such clinical manifestation and present it in this report.

\section{Case Report}

Healthy 73-year-old man was admitted for elective total knee arthroplasty. The operation was uneventful and the patient started rehabilitation the following post-operative day with continuous passive motion (CPM) of the operated knee, aided walking and muscle strengthening. According to the anticoagulant protocol he was treated by subcutaneous injections of enoxaparin $40 \mathrm{mg}$ once a day starting 24 hours after surgery.

On the fourth post operative day a routine blood count indicated thrombocytopenia of $60,000 / \mu \mathrm{L}$. Accordingly heparin induced thrombocytopenia (HIT) was diagnosed. The enoxaparin administration was discontinued and the patient remained under observation.

On the fifth post operative day the patient developed respiratory difficulty accompanied by a low blood pressure (90/40 mmHg), signs of skin necrosis at the site of the previous sub-cutaneous injection of the enoxaparin (Figure 1). Pulmonary embolus was suspected but ruled out by a pulmonary CT angiogram. Additionally deep vein thrombosis in the lower limbs was ruled out by ultrasound doppler examination. The clinical signs of hemodynamic shock in this patient were obvious, therefore he was transferred to the intensive care unit. Blood tests for cardiac markers, blood culture, urine culture, chest $\mathrm{X}$ rays, echocardiography and lumbar puncture were all in a normal range.

At the intensive care unit an intravenous antibiotic treatment with Vancomycine $2 \mathrm{gr} / \mathrm{day}$ and piperacillin sodium with tazobactam sodium $13.5 \mathrm{gr} /$ day was commenced. The general condition of the patient gradually deteriorated and on the 10th day endotracheal artificial ventilation was started.

CT scan demonstrated thickening of the skin and sub cutaneous tissue at the injection site extending from the left lower rib to the pelvic region. (Figure 2)

On the $12^{\text {th }}$ day the patient deteriorated more and treatment with inotropic drugs to maintain blood pressure was started. On the chest CT scan pleural and pericardial effusions were evident. On the 28th day of hospitalization the patient died due to septic shock.

\section{Discussion}

Skin necrosis occurring after administration of a low-molecular-weight heparin is rare, and the pathogenesis of this complication is not well understood. In the presented patient heparin-induced thrombocytopenia (HIT) and

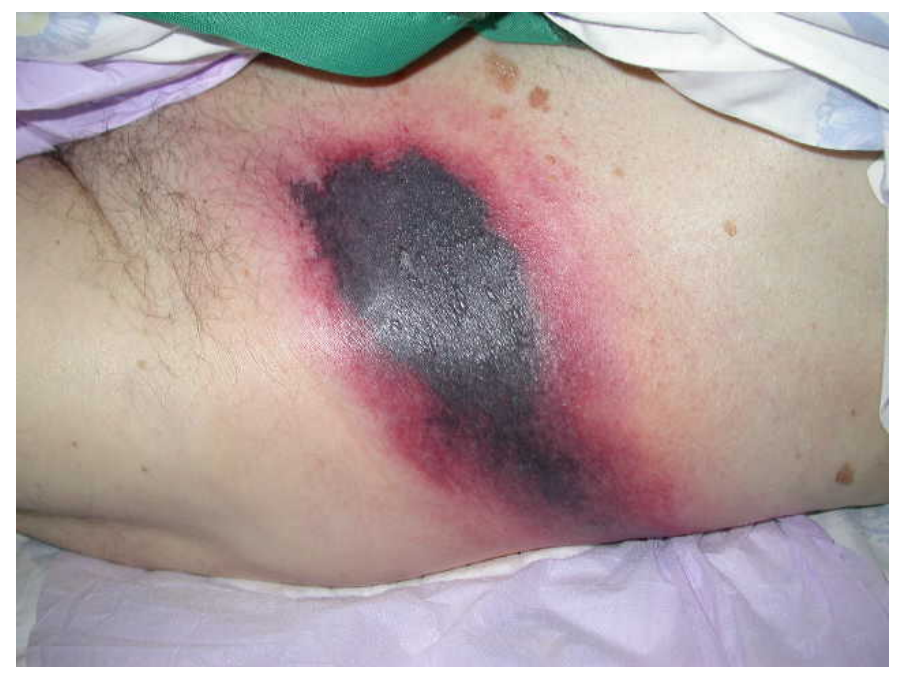

Figure 1. Skin necrosis developed on the left flank 24 hours after and at the sight of $40 \mathrm{mg}$ enoxaparin subcutaneous injection. 


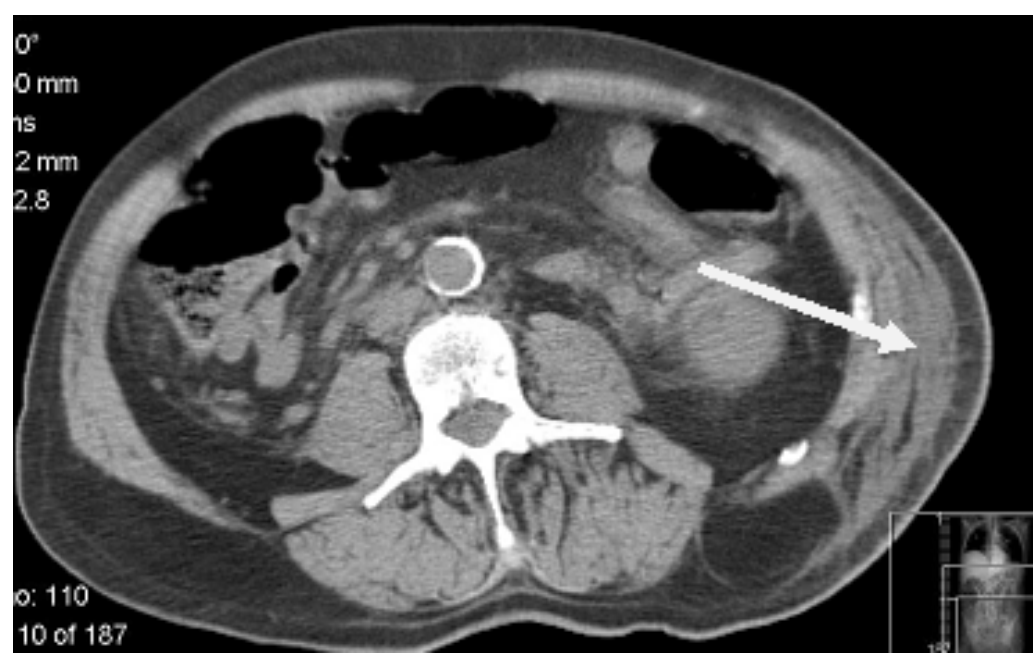

Figure 2. ST scan image of subcutaneous necrosis at the left flank area, below the 12 th rib (indicated by an arrow).

skin necrosis at the site of the injected enoxaparin has triggered the fatal chain of events. The HIT is a phenomenon caused by the use of heavy weight heparin. It appears rarely with low molecular weight heparin. In general the secession of the drug administration reverses the thrombocytopenia to the normal values. Extensive skin necrosis even when HIT occurs is very rare [5]. According to the published reports the patients who developed this type of condition were treated successfully with local excision [6]-[9]. In one single previous report the outcome was fatal [10]. In our patient the necrotic tissue was the source of sepsis and ultimately with the fatal consequence. According to patient's gradual deterioration and due to the extent of the skin necrosis area surgical intervention was postponed. We can't deduce from the scarce published data on this rare condition if this decision was justified.

\section{Conclusion}

By this report we would like to emphasize the possibility of a devastating complication of the routine treatment by subcutaneous injection of LMWH. Since this type of treatment is very common, an early recognition of the development of HIT with skin necrosis might justify an aggressive local surgical treatment that might prevent a fatal outcome. Currently there is no clear support in the previously published data that supports this clinical approach.

\section{References}

[1] Noble, S., Peters, D.H. and Goa, K.L. (1995) Enoxaparin: A Reappraisal of Its Pharmacology and Clinical Applications in the Prevention and Treatment of Thromboembolic Disease. Drugs, 49, 388-410. http://dx.doi.org/10.2165/00003495-199549030-00006

[2] Spiro, T.E., Johnson, G.J., Christie, M.J., Lyons, R.M., MacFarlane, D.E., Blasier, R.B. and Tremaine, M.D. (1994) Efficacy and Safety of Enoxaparin to Prevent Deep Venous Thrombosis after Hip Replacement Surgery. Enoxaparin Clinical Trial Group. Annals of Internal Medicine, 121, 81-89. http://dx.doi.org/10.7326/0003-4819-121-2-199407150-00001

[3] Manoharan, A. (1992) Heparin-Induced Skin Reaction with Lowmolecular-Weight Heparin. European Journal of Haematology, 48, 234. http://dx.doi.org/10.1111/j.1600-0609.1992.tb01592.x

[4] Phillips, J.K., Majumdar, G., Hunt, B.J. and Savidge, G.F. (1993) Heparin-Induced Skin Reaction Due to Two Different Preparations of Low Molecular Weight Heparin (LMWH). British Journal of Haematology, 84, 349-350. http://dx.doi.org/10.1111/j.1365-2141.1993.tb03080.x

[5] Ojeda, E., Perez, M.C., Mataix, R., Arbelo, A., Jimenez, S., Campo, C. and Balda, I. (1992) Skin Necrosis with Low Molecular Weight Heparin. British Journal of Haematology, 82, 620. http://dx.doi.org/10.1111/j.1365-2141.1992.tb06477.x

[6] Toll, A., Gallardo, F., Abella, M.E., Fontcuberta, J., Barranco, C. and Pujol, RM. (2005) Low-Molecular-Weight He- 
parin-Induced Skin Necrosis: A Potential Association with Pre-Existent Hypercoagulable States. International Journal of Dermatology, 44, 964-966. http://dx.doi.org/10.1111/j.1365-4632.2004.02326.x

[7] Antonelli, D., Fares, L. andAnene, C. (2000) Enoxaparin Associated with Hugh Abdominal Wall Hematomas: A Report of Two Cases. The American Surgeon, 66, 797-800.

[8] Tonn, M.E., Schaiff, R.A. and Kollef, M.H. (1997) Enoxaparin-Associated Dermal Necrosis: A Consequence of CrossReactivity with Heparin-Mediated Antibodies. Annals of Pharmacotherapy, 31, 323-326.

[9] Fried, M., Kahanovich, S. and Dagan, R. (1996) Enoxaparin-Induced Skin Necrosis. Annals of Internal Medicine, 125, 521-522. http://dx.doi.org/10.7326/0003-4819-125-6-199609150-00036

[10] Singh, S., Verma, M., Bahekar, A., Agrawal, P., Duggal, J., Iliescu, M., Khosla, P. and Muzaffar, S. (2007) Enoxaparin-Induced Skin Necrosis: A Fatal Outcome. American Journal of Therapeutics, 14, 408-410. http://dx.doi.org/10.1097/MJT.0b013e3180325905 